Saudi Journal of Oral and Dental Research

Abbreviated Key Title: Saudi J Oral Dent Res

ISSN 2518-1300 (Print) |ISSN 2518-1297 (Online)

Scholars Middle East Publishers, Dubai, United Arab Emirates

Journal homepage: https://saudijournals.com/sjodr

\title{
Mandibular Canine with Two Canals: A Case Report in Saudi Arabia
}

Ethar Hassan Abulhassan ${ }^{1 *}$, Iman Emad Almohammed ${ }^{2}$, Sarah Mubarak Alkahtany ${ }^{3}$

${ }^{1,2}$ Intern, College of Dentistry, King Saud University

${ }^{3}$ Lecturer, Department of Restorative Dental Sciences, College of Dentistry, King Saud University

\author{
DOI: $10.36348 /$ sjodr.2020.v05i01.010 \\ | Received: 02.01.2020 | Accepted: 17.01.2020 | Published: 22.01.2020 \\ *Corresponding author: Ethar Hassan Abulhassan
}

\section{Abstract}

The Knowledge of the root canal morphology is essential for the success of the endodontic treatment. The most common anatomical configuration in mandibular canines is to have one root with one canal. However, previous studies reported 4.6 to $15 \%$ of the cases to have a second canal. In order to increase the knowledge about root canal morphology in Saudi population, we reported a clinical case about successful endodontic management of mandibular canine with two joined canals (Vertucci type II) in Saudi female.

Keywords: Endodontics; mandibular canine; root canal configuration.

Copyright @ 2020: This is an open-access article distributed under the terms of the Creative Commons Attribution license which permits unrestricted use, distribution, and reproduction in any medium for non-commercial use (NonCommercial, or CC-BY-NC) provided the original author and source are credited.

\section{INTRODUCTION}

Endodontic practice requires clinician's awareness about different anatomical configuration of the root canal system [1-3]. The knowledge of the root canal morphology and the assessment of the preoperative radiographs were always essential to the success of root canal treatment (RCT) [4-8]. Previous published investigations have described the root canal morphology of different permanent teeth, including mandibular canine. The reported configuration and number of root canals in permanent mandibular canine had high variation among different studies [9-11].

The majority of mandibular canines have only one canal $[4,11,12]$. However, two canals with one or two foramen have been reported to be approximately $15 \%$ [9, 11]. Wang, Zhange et al. reported $4.9 \%$ of the examined mandibular canine to have two canals and one foramen, and $1.2 \%$ contain two canals and two foramina [13].

Most published anatomical studies were conducted in western population. Only one published study reported the incidence of 2 canals in Saudi population (Al-Dahman et al.). Few Case reports were found in the literature about clinical cases with 2 canals [5, 14-16]. In the current report, a clinical case was presented about successful endodontic management of mandibular canine with 2 canals in Saudi female, in order to add to the current knowledge about root canal morphology in Saudi population.

\section{CASE REPORT}

A 52-year-old Saudi female patient with no relevant medical condition was referred to King Saud University, College of dentistry, to endodontically treat the lower left canine. Past dental history showed multiple root canal treatments and fixed partial denture. Upon clinical examination, cervical caries was detected facially; the tooth was negative to percussion and palpation. With thermal testing, the tooth showed lingering pain. Preoperative periapical radiograph of tooth \#33 showed cervical caries with normal periapical tissues (figure 1). Tooth was diagnosed as asymptomatic irreversible pulpitis with normal apical tissue. No mobility or deep pockets were found. The Endodontic treatment plan was non-surgical root canal treatment. The treatment was scheduled and initiated after obtaining a written informed consent from the patient.

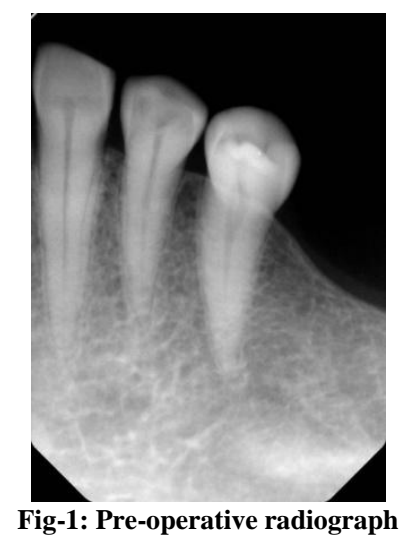


Local anesthesia (2\% xylocaine with 1:80,000 epinephrines) was introduced through infiltration and the tooth was isolated with rubber dam using ivory 9 clamps. Facial caries removed with round bur (size 2) and the cavity was prepared to gain the access to the root canal system. Lingual extension of the access cavity was performed to expose the second canal (Figure 2). The pulp chamber was accessed, and both the buccal and lingual canals were located under magnification (X2). The working length for both canals was established with apex locator (DENTA PROT ZX) and confirmed with radiographs (Figure 3).

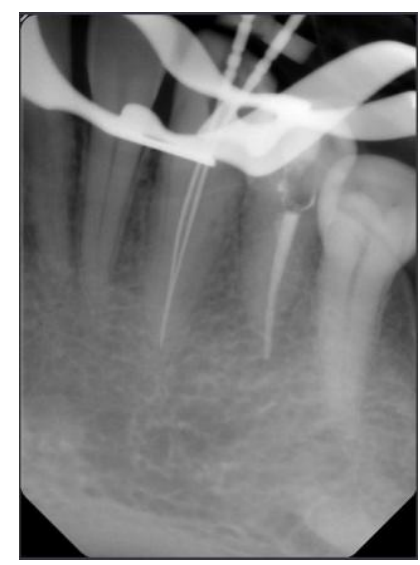

Fig-2: access cavity preparation from the facial aspect

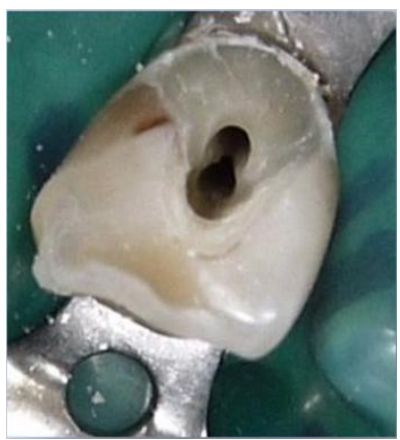

Fig-3 (missing): Working length radiographs confirmed the root canal configuration. The two canals are joined at the apical third

The root canal configuration consisted of two canals leaving the floor of the pulp chamber and existing at a single apical foramen. The cervical parts of the canals were preflared with Gates-Glidden burs (Dentsply Maillefer- size 2). The canals were instrumented with profile rotary system using crown down instrumentation technique up to size $35 \backslash 04$. The root canals were irrigated with $10 \mathrm{ml} 2.5 \%$ sodium hypochlorite during the preparation procedure. $17 \%$ ethylenediaminetetraacetic (EDTA) $5 \mathrm{ml}$ was used as a final irrigant for smear layer removal. The canals were obturated with lateral condensation technique (Figure 4 and 5). After obturation, the access cavity was sealed with a layer of GIC (GC Fuji II LC, United states) and composite resin restoration (Dentsply Spectrum, United states).

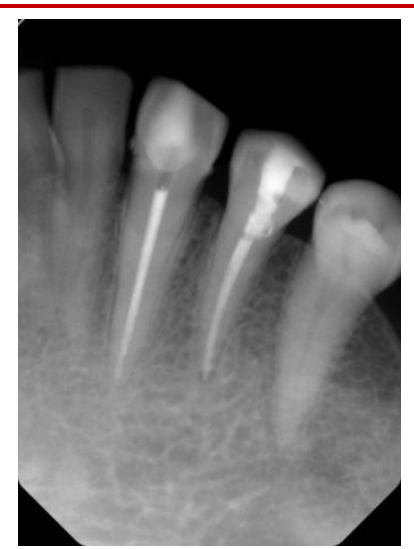

Fig-4: Final straight radiograph after obturation

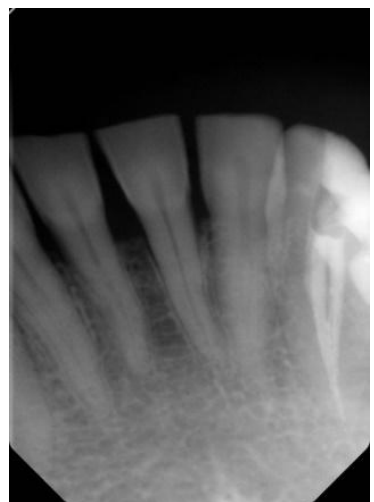

Fig-5: Final mesial angulation radiograph after obturation

\section{DISCUSSION}

RCT is indicated for mandibular canines due to caries, erosion, attrition, or trauma. Moreover, intentional is frequently needed for prosthetic reason, especially for overdenture abutments. Before initiating any endodontic treatment, it is essential to predict the root canal configuration from previous knowledge and careful assessment of preoperative radiographs [17]. Furthermore, the presence of a second canal could be expected if the contralateral canine have two canals. Recent CBCT studies found that $91-97 \%$ of the cases have a symmetrical anatomical configuration $[12,18$, 19]. The expected root canal configuration will be confirmed clinically after access cavity preparation and locating all canals. The relation between the canals can be predicted from the orifices proximity, the probability of canals being joined will increase if canal orifices are closer to each other [20].

International studies reported $5-15 \%$ of mandibular canines to have two canals [9-11, 13, 20]. Different root canal configurations were reported in Saudi population [5, 14-16]. Recently, Aldahman et al. performed a CBCT anatomical assessment of mandibular canines in Saudi population. Their results revealed that $4.6 \%$ of mandibular canines have two canals [12]. Alenezi and Al-Hawwas reported a case of mandibular canine with one root and Vertucci type II root canal configuration (two canals joined apically) in a Saudi male patient [5]. Another case was reported of 
Saudi female patients with the same configuration in mandibular canine [15]. In the literature, we found contradicting results of the number of canals among male and female patients [21, 19]. According to AlDahman et al. the two canals configuration in a mandibular canine had a higher incidence in male compared to female patients in Saudi subpopulation [12].

\section{CONCLUSION}

The current reported case was a management of canine with two canals in a Saudi female patient. This emphasizes the importance of expecting different root canal configurations in all patients regardless of the gender. Clinicians are encouraged to review the root canal morphology of different teeth. All efforts should be made to detect all existing canals in the root canals system through proper assessment of pre-operative radiographs and careful examination of the pulp chamber.

\section{REFERENCES}

1. Friedman, S. (2002). Prognosis of initial endodontic therapy. Endodontic topics, 2(1):59-88.

2. Cleghorn, B.M., Christie, W.H., Dong, C.C. (2008). Anomalous mandibular premolars: a mandibular first premolar with three roots and a mandibular second premolar with a C- shaped canal system. International endodontic journal, 41(11):1005-14.

3. Somalinga, Amardeep, N., Raghu, S., Natanasabapathy, V. (2014). Root canal morphology of permanent maxillary and mandibular canines in Indian population using cone beam computed tomography. Anatomy research international.

4. Wang, L., Zhang, R., Peng, B.(2009). Clinical Features and treatment of mandibular canines with two root canals: Two case reports. Chinese Journal of Dental Research, 1;12(1):61.

5. Alenezi, M.A., Al-Hawwas, A.Y.(2016). Permanent mandibular canine with two roots and two root canals: Two case reports. Saudi Endodontic Journal, 1;6(2):98.

6. Sjögren, U.L., Hägglund, B., Sundqvist, G., Wing, K.(1990). Factors affecting the long-term results of endodontic treatment. Journal of endodontics, 1;16(10):498-504.7.

7. Vertucci, F.J. (2005). Root canal morphology and its relationship to endodontic procedures. Endodontic topics, 10(1):3-29.8.

8. Cantatore, G., Berutti, E., Castellucci, A. (2006). Missed anatomy: frequency and clinical impact. Endodontic Topics, 15(1):3-1.
9. Pineda, F., Kuttler, Y. (1972). Mesiodistal and buccolingual roentgenographic investigation of 7,275 root canals. Oral Surgery, Oral Medicine, Oral Pathology, 1;33(1):101-10.

10. Green, D. (1973). Double canals in single roots. Oral Surgery, Oral Medicine, Oral Pathology. 1973 May 1;35(5):689-96.

11. Vertucci, F.J.(1984). Root canal anatomy of the human permanent teeth. Oral surgery, oral medicine, oral pathology, 1;58(5):589-99.

12. Al-Dahman, Y., Alqedairi, A., Alfawaz, H., Alnassar, F., Al-Jebaly, A. (2019). Cone-beam computed tomographic evaluation of root canal morphology of mandibular canines in a Saudi subpopulation. Saudi Endodontic Journal, 1;9(2):113.

13. Pécora, J.D., Sousa, M.N., Saquy, P.C. (1993). Internal anatomy, direction and number of roots and size of human mandibular canines. Brazilian dental journal, 4(1):53-7.

14. Rahmatulla, M., Wyne, A.H. (1993). Bifid roots in a mandibular canine: Report of an unusual case. Saudi Dent J, 5:77-8.

15. Balto, H.A., Al-Wakeel, M. (2007). Mandibular canine with two root canals-Case Report. Egypt Dent J.;53:2535-8.

16. Van der Vyver, P.J., Jonker, C.H. (2018). Root canal treatment in mandibular canines with two roots: a review of the literature and a report of three cases. South African Dental Journal, 73(8):507-13.

17. Fava, L.R., Dummer, P.M. (1997). Periapical radiographic techniques during endodontic diagnosis and treatment. International Endodontic Journal, Jul;30(4):250-61.

18. Mashyakhy, M. (2019). Prevalence of a Second Root and Canal in Mandibular and Maxillary Canines in a Saudi Arabian Population: A Conebeam Computed Tomography Study. The journal of contemporary dental practice, 1;20(7):773-7.

19. Soleymani, A., Namaryan, N., Moudi, E., Gholinia, A. (2017). Root canal morphology of mandibular canine in an Iranian population: a CBCT assessment. Iranian endodontic Journal, 12(1):78.

20. Alapati, S., Zaatar, E.I., Shyama, M., Al-Zuhair, N. (2006). Maxillary canine with two root canals. Medical Principles and Practice, 15(1):74-6.

21. Kaffe, I., Kaufman, A., Littner, M.M., Lazarson, A. (1985). Radiographic study of the root canal system of mandibular anterior teeth. International Endodontic Journal, 18(4):253-9. 